\title{
X-ray Photoelectron Spectroscopy Analysis of Wood Degradation in Old Architecture
}

\author{
He Sun, ${ }^{\mathrm{b}, 1}$ Yan Yang, ${ }^{\mathrm{a}, *, 1}$ Yanxia Han, ${ }^{\mathrm{a}}$ Mingjin Tian, ${ }^{\mathrm{a}}$ Bin Li, ${ }^{\mathrm{a}} \mathrm{Li}$ Han, ${ }^{\mathrm{c}}$ Aifeng Wang, ${ }^{\mathrm{a}}$ \\ Wei Wang, ${ }^{a}$ Rui Zhao, ${ }^{a}$ and Yiming $\mathrm{He}^{\mathrm{a}}$ \\ To investigate the decay mechanisms of red oak (Quercus rubra) and \\ hemor (Schima spp.) woods in the old architectural structure of Xichuan \\ Guild Hall, chemical composition changes were determined and analyzed \\ with X-ray photoelectron spectroscopy (XPS). The results showed that \\ decaying resulted in a noticeable decrease of the O/C from 0.59 to 0.42 in \\ the red oak wooden components. The increase of $\mathrm{C}_{1}$ contribution, \\ decrease of $\mathrm{C}_{4}$ contribution, increase of $\mathrm{O}_{1}$ and $\mathrm{O}_{3}$ contributions, and \\ decrease of $\mathrm{O}_{2}$ contribution indicated that the carbohydrates in red oak \\ wooden components can be easily degraded by fungi compared with \\ lignin. Moreover, decaying resulted in a slight decrease of the $\mathrm{O} / \mathrm{C}$ from \\ 0.49 to 0.47 in the hemor wooden components. The results of increase of \\ $\mathrm{C}_{1}$ contribution, decrease of $\mathrm{C}_{3}$ and $\mathrm{C}_{4}$ contributions, increase of $\mathrm{O}_{1}$, and \\ decrease of $\mathrm{O}_{2}$ and $\mathrm{O}_{3}$ contributions indicated that carbohydrate and lignin \\ were all degraded by fungi.
}

Keywords: Xichuan Guild Hall, Old architectures; Wooden components; Degradation behavior; Chemical composition changes; XPS

Contact information: a: School of Architecture, Nanyang Institute of Technology, Nanyang City, Henan Province, 473000, P.R. China; b: College of Material Science and Engineering, Southwest Forestry University, Kunming City, Yunnan Province,650224, P.R. China; c: Henan Key Laboratory of Zhang Zhongjing Formulae and Herbs for Immunoregulation, Nanyang Institute of Technology, Nanyang City, Henan Province, 473000, P.R. China; 1: He Sun and Yan Yang contributed equally to this work; * Corresponding author: yangyanrainy@163.com

\section{INTRODUCTION}

The Xichuan Guild Hall, which was built in 1910, is located in Henan Province, China, and it is considered a key cultural relic protection unit of Nanyang City. However, its wooden components have changed greatly in the past hundred years. Alterations on their anatomical structure, chemical composition degradation, and the decreased quality of their physical and mechanical properties reduce their residual mechanical strength and eventually affect their quality and life span (Ferraz et al. 1995; Choi et al. 2006; Arias et al. 2010; Koyani et al. 2014; Bari et al. 2019; Brischke et al. 2019; Chang et al. 2019; Gao et al. 2019; Li et al. 2019). Analyzing the changes in their chemical compositions can provide reference and guidance for the research of degradation mechanisms, maintenance, and reinforcement of decayed wooden components in the future.

X-ray photoelectron spectroscopy (XPS) (Stark et al. 2004, 2007; Inari et al. 2011; Huang et al. 2012; Xu et al. 2013; Tomak et al. 2013; Fernández-Fernández et al. 2014; Banuls-Ciscar et al. 2016; Croitoru et al. 2018) is an effective technique for investigating the chemistry of woods, especially decayed ones (Dey et al. 1992; Ferraz et al. 1995). Its advantage is that it requires minimal sample preparation and quantity compared with conventional gravimetric techniques (Xu et al. 2013). 
This study examined the changes of chemical compositions and investigated the degradation mechanisms of wooden components in the old wooden structure of Xichuan Guild Hall. XPS was used for chemical analyses to provide insights into the degradation process for decayed and non-decayed wooden components exposed to fungi in with longterm usage.

\section{EXPERIMENTAL}

\section{Materials}

Samples (Table 1) were collected from the decayed wooden components of the Xichuan Guild Hall in Nanyang City, Henan Province, China. Among the wooden component samples, sample No. 3, Quercus rubra (Fagaceae), which was identified by Yan Yang et al. (2020), was obtained from the surface of wooden beam' tops, and sample No. 1, Schima spp. (Theaceae) which was identified by Yang et al. (2020), was obtained from the surface of wooden column' roots. Samples of the non-decayed red oak and hemor woods were obtained from model specimens of the Southwest Forestry University. Radial sections (Entrapment treatment of the sample seen from the paper conducted by Yang et al. (2020) were sliced using a microtome (SM2000R, Leica company) for XPS analysis.

Table 1. Information about the Materials

\begin{tabular}{|c|c|c|c|}
\hline \multicolumn{3}{|c|}{ Samples } & \multirow{2}{*}{ Sample location } \\
\hline No. & Full name & Abbreviation & \\
\hline No. 3 & Decayed red oak wood & DROW & Wooden column \\
\hline Control & $\begin{array}{c}\text { Non-decayed red oak } \\
\text { wood }\end{array}$ & NDROW & $\begin{array}{c}\text { Model specimens of the Southwest } \\
\text { Forestry University }\end{array}$ \\
\hline No. 1 & Decayed hemor wood & $\mathrm{DHW}$ & Wooden beam \\
\hline Control & $\begin{array}{l}\text { Non-decayed hemor } \\
\text { wood }\end{array}$ & NDHW & $\begin{array}{c}\text { Model specimens of the Southwest } \\
\text { Forestry University }\end{array}$ \\
\hline
\end{tabular}

\section{XPS Analysis}

XPS analyses were performed using a VG MKII system (MultiPak V9.3, Kanagawa-ken, Japan) with a Mg K $\alpha$ X-ray source. The samples were analyzed at a $10^{-6}$ $\mathrm{Pa}$ pressure with a $20 \mathrm{eV}$ pass energy, $8 \mathrm{kV}$ operating voltage, $30 \mathrm{~mA}$ operating current, and $0.1 \mathrm{eV}$ resolution at a temperature of $20^{\circ} \mathrm{C}$ to $400{ }^{\circ} \mathrm{C}$ and then thoroughly cleaned and degreased before the removal of wood water. All samples were removed immediately before examination to minimize contact with bare hands. After preparation, the samples were immediately placed in a vacuum chamber.

The following three types of spectra were collected: a low-resolution spectrum (survey spectrum) from $0 \mathrm{eV}$ to $1100 \mathrm{eV}$, a high-resolution spectrum of the $\mathrm{C} 1 \mathrm{~s}$ region from $278 \mathrm{eV}$ to $298 \mathrm{eV}$, and a high-resolution spectrum of the $\mathrm{O} 1 \mathrm{~s}$ region from $523 \mathrm{eV}$ to $543 \mathrm{eV}$ (Yang et al. 2018; Stark et al. 2007). The oxygen to carbon ratio (O/C) was determined from the low-resolution spectra. The $\mathrm{C} 1 \mathrm{~s}$ peak from the high-resolution spectra was deconvoluted into four subpeaks, namely, an unoxidized carbon, i.e., $\mathrm{C}_{1}$, and oxidized carbons, i.e., $\mathrm{C}_{2}, \mathrm{C}_{3}$, and $\mathrm{C}_{4}$ by using Origin 8.5 software (OriginLab, Northampton, MA, USA).

The oxygenated to unoxygenated carbon ratio $\left(\mathrm{C}_{\mathrm{ox}} / \mathrm{C}_{\mathrm{unox}}\right)$ was calculated using the sum of $C_{2}, C_{3}$, and $C_{4}$ to $C_{1}$ ratio (Matuana et al. 2002; Stark et al. 2007, 2004). The O1s 
peak from the high-resolution spectra was deconvoluted into three subpeaks, that is, $\mathrm{O}_{1}$, $\mathrm{O}_{2}$, and $\mathrm{O}_{3}$ by using Origin 8.5 software.

\section{RESULTS AND DISCUSSION}

\section{XPS Analysis of Red Oak Wooden Components}

XPS survey spectrum analysis of the wood surfaces

The survey spectra of $\mathrm{C} 1 \mathrm{~s}$ and $\mathrm{O} 1 \mathrm{~s}$ were obtained to evaluate the chemical structures of the surfaces of the red oak wooden components in decayed and non-decayed samples, and the results are presented in Fig. 1. The experimental atomic compositions, atomic percentages, and $\mathrm{O} / \mathrm{C}$ of wood surfaces are shown in Table 2.

Survey spectrum analysis revealed that $\mathrm{C}$ and $\mathrm{O}$ atoms are the major elements located at the binding energy (BE) values from $284 \mathrm{eV}$ to $290 \mathrm{eV}$ and from $531 \mathrm{eV}$ to 534 $\mathrm{eV}$, respectively. Small amounts of nitrogen $(\mathrm{N})$, silicon $(\mathrm{Si})$, and calcium $(\mathrm{Ca})$ atoms were also found on the wood surfaces at BE values of approximately 396.91, 98.91 (or 149.91), and $345 \mathrm{eV}$, respectively (Fig. 1 and Table 2) (Popescu et al. 2009; Xu et al. 2013). In principle, the $\mathrm{O} / \mathrm{C}$ values are 0.83 for cellulose, approximately 0.8 for hemicellulose, and 0.33 for lignin (Inari et al. 2006; Kocaefe et al. 2013). A high O/C usually indicates a high relative content of carbohydrates. Conversely, a low $\mathrm{O} / \mathrm{C}$ indicates a high relative content of lignin (Li et al. 2005; Kocaefe et al. 2013).

The relative content of the $\mathrm{C}$ atom of red oak increased from 61.4 in the nondecayed sample to 67.8 in the decayed sample, whereas that of $\mathrm{O}$ atom decreased from 36.5 to 28.2 (Fig. 1 and Table 2).

Decaying reduced the $\mathrm{O} / \mathrm{C}$ from 0.59 to 0.42 at a decrease percentage of approximately $28.8 \%$. This finding indicates reduction in the predominant oxygencontaining functional groups, such as carboxyl, acetyl, and hydroxyl groups on the surfaces of the decayed woods. Therefore, the relative content of lignin increased, whereas that of carbohydrates decreased. These findings were in good agreement with those for Pinus massoniana decayed by brown-rot fungi (Li et al. 2018).
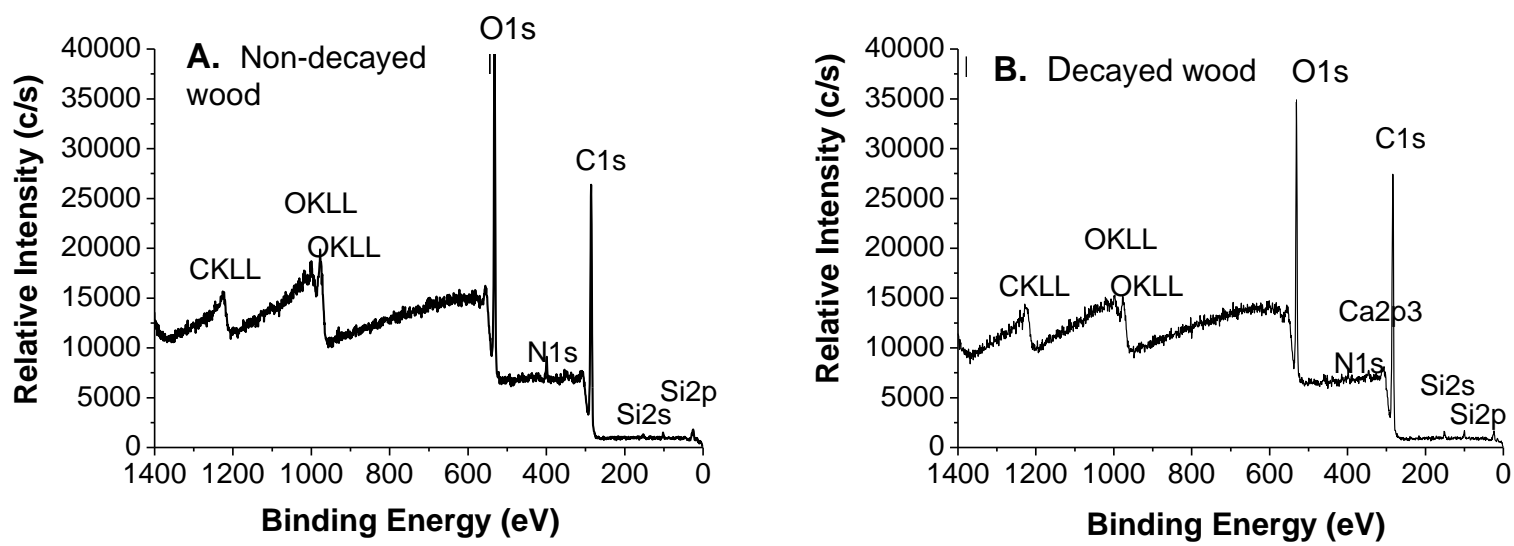

Fig. 1. XPS survey spectra of the red oak wooden components 
Table 2. The Experimental Atomic Compositions, Atomic Percentage, and Ratio of Oxygen to Carbon (O/C) of Wood Surfaces Obtained by XPS Analysis

\begin{tabular}{|c|c|c|c|c|c|c|c|}
\hline \multicolumn{2}{|c|}{ Samples } & C1s(\%) & O1s(\%) & N1s(\%) & Si2p(\%) & Ca2p(\%) & O/C \\
\hline \multirow{2}{*}{ NDROW } & $\mathrm{M}$ & 61.4 & 36.5 & 2.1 & 1.0 & - & 0.59 \\
\cline { 2 - 8 } & $\mathrm{S}$ & 1.25 & 1.02 & 0.05 & 0.04 & - & 0.05 \\
\hline \multirow{2}{*}{ DROW } & $\mathrm{M}$ & $67.8 \uparrow$ & $28.2 \downarrow$ & 2.6 & 1.1 & 0.3 & $0.42 \downarrow$ \\
\cline { 2 - 8 } & $\mathrm{S}$ & 1.35 & 0.89 & 0.06 & 0.04 & 0.04 & 0.09 \\
\hline \multicolumn{2}{|c|}{ Changes } & $+10.42 \%$ & $-22.74 \%$ & $+23.81 \%$ & $+10.00 \%$ & - & $-28.81 \%$ \\
\hline \multirow{2}{*}{ NDHW } & $\mathrm{M}$ & 64.9 & 31.9 & 2.7 & 0.5 & - & 0.49 \\
\cline { 2 - 8 } & $\mathrm{S}$ & 2.01 & 1.53 & 0.87 & 0.21 & - & 0.02 \\
\hline \multirow{2}{*}{ DHW } & $\mathrm{M}$ & $66.1 \uparrow$ & $31.3 \downarrow$ & 1.8 & 0.7 & - & $0.47 \downarrow$ \\
\cline { 2 - 8 } & $\mathrm{S}$ & 1.33 & 1.12 & 0.09 & 0.12 & - & 0.05 \\
\hline \multicolumn{2}{|c}{ Changes } & $+1.85 \%$ & $-1.88 \%$ & $-33.33 \%$ & $+40.00 \%$ & - & $-4.08 \%$ \\
\hline
\end{tabular}

Sample descriptions: NDROW-the non-decayed red oak wood; DROW- the decayed red oak wood; NDHW- the non-decayed hemor wood; DHW- the decayed hemor wood. "+"- increase percentage; "-"- decrease percentage. M- Mean value; S- Standard deviation.

\section{Cls spectra analysis of the wood surfaces}

The deconvoluted high-resolution XPS spectra of C1s peak in lignocellulosic materials are usually assigned to four classes of carbon atoms expressed as $\mathrm{C}_{1}, \mathrm{C}_{2}, \mathrm{C}_{3}$, and $\mathrm{C}_{4}$ (Inari et al. 2006; Popescu et al. 2009). The deconvoluted peaks with corresponding theoretical BE values and bond type for the high-resolution XPS scan of $\mathrm{C} 1 \mathrm{~s}$ are presented in Table 3. The $\mathrm{C}_{1}$ class of carbon atoms is ascribed to carbon atoms that are bonded only to carbon or hydrogen atoms, i.e., $\mathrm{C}-\mathrm{H}$ or $\mathrm{C}-\mathrm{C}$ and originates mainly from phenyl propane structures in the lignin component of the wood and extractives consisting of fatty acids, fats, waxes, and terpenoids. The $\mathrm{BE}$ value of $\mathrm{C}_{1}$ is low at approximately $284.8 \mathrm{eV}$ (Inari et al. 2006; Popescu et al. 2009; Wang et al. 2009). $C_{1}$ is referred to as unoxygenated carbon atom $\left(\mathrm{C}_{\mathrm{unox}}\right)$. The $\mathrm{C}_{2}$ class of carbon atom contains carbon atoms that are bonded to one noncarbonyl oxygen atom, i.e., $\mathrm{C}-\mathrm{OH}, \mathrm{C}-\mathrm{O}-\mathrm{C}$ and is mainly derived from cellulose and hemicellulose containing a large quantity of hydroxyl groups (-OH). Accordingly, the $\mathrm{BE}$ value of $\mathrm{C}_{2}$ is higher than that of $\mathrm{C}_{1}$ at approximately $286.5 \mathrm{eV}$ (Inari et al. 2006; Popescu et al. 2009; Wang et al. 2009). The $\mathrm{C}_{2}$ class is referred to as oxygenated carbon atom $\left(\mathrm{C}_{\mathrm{ox}}\right)$. The $\mathrm{C}_{3}$ class of carbon atom corresponds to carbon atoms that are bonded to one carbonyl oxygen atom or two non-carbonyl oxygen atoms, i.e., $\mathrm{C}=\mathrm{O}$ or $\mathrm{O}-\mathrm{C}-\mathrm{O}$ and is derived from the acetal structure (O-C-O) of cellulose and hemicellulose and the carbonyl structure $(\mathrm{C}=\mathrm{O})$ of lignin. The high oxidation states of carbon atoms in $\mathrm{C}=\mathrm{O}$ and $\mathrm{O}-\mathrm{C}-\mathrm{O}$ lead to high $\mathrm{BE}$ values of approximately $288 \mathrm{eV}$ to $288.5 \mathrm{eV}$ (Inari et al. 2006; Popescu et al. 2009; Wang et al. 2009). The $\mathrm{C}_{3}$ class is referred to as oxygenated carbon atom $\left(\mathrm{C}_{\mathrm{ox}}\right)$. The $\mathrm{C}_{4}$ class of carbon atom is associated with carbon atoms that are bonded to one carbonyl oxygen atom and one non-carbonyl oxygen atom, i.e., $\mathrm{O}-\mathrm{C}=\mathrm{O}$. These atoms are acetyl groups and glucuronic acid present in hemicellulose and extractives, such as resin acids, fatty acids, and other substances. $\mathrm{C}_{4}$ has the highest $\mathrm{BE}$ value $(289 \mathrm{eV})$ among carbon atom classes because it has the highest oxidation state (Inari et al. 2006; Popescu et al. 2009). The $\mathrm{C}_{4}$ class is also referred to as oxygenated carbon atom $\left(\mathrm{C}_{\mathrm{ox}}\right)$.

The high-resolutions of $\mathrm{C} 1 \mathrm{~s}$ of the surfaces of red oak wooden components in decayed and non-decayed samples were deconvoluted into four subpeaks by using Origin 8.5 software as shown in Fig. 2. The BE values, peak area, and $\mathrm{C}_{\mathrm{ox}} / \mathrm{C}_{\mathrm{unox}}$ for decomposed carbon peaks for all samples are presented in Table 4. The $\mathrm{C}_{1}$ contributions increased noticeably from $22.4 \%$ to $35.8 \%$ with an increase percentage of approximately $59.9 \%$. This 
finding indicates that the carbohydrates were considerably decayed by fungi, leading to an increase in $\mathrm{C}-\mathrm{C}$ bonds and lignin and extractive contents. Meanwhile, the contributions of $\mathrm{C}_{2}$ and $\mathrm{C}_{3}$ increased from $51.3 \%$ to $53.8 \%$ and $6.2 \%$ to $9.1 \%$, respectively, after decay. These results implied an increase in the hydroxyl groups $(-\mathrm{OH})$ and acetal structure $(\mathrm{O}-\mathrm{C}$ O) mainly derived from cellulose and hemicellulose. However, the $\mathrm{C}_{4}$ contributions decreased rapidly from $20.0 \%$ to $1.28 \%$ with a decrease percentage of approximately 93.6\%. This finding indicates that the hemicellulose was considerably decayed by fungi, leading to a sharp decrease in the acetyl groups and glucuronic acid. These changes in $\mathrm{C}_{1}$, $\mathrm{C}_{2}, \mathrm{C}_{3}$, and $\mathrm{C}_{4}$ relative contents indicated that carbohydrates, especially cellulose, in red oak wooden components can be easily degraded by fungi compared with lignin. These findings were in good agreement with the results presented by Xu et al. (2013) and Li et al. (2018).

The $\mathrm{C}_{\mathrm{ox}} / \mathrm{C}_{\text {unox }}$ ratio decreased from 3.46 to 1.79 with decrease percentage of approximately $48.3 \%$ after decay (Table 4). This result indicates that the carbohydrates were considerably decayed by fungi and suggests the decrease in oxygen-containing functional groups during the decay process. These findings were in good agreement with those by Xu et al. (2013).

In general, brown-rot fungi degrade cellulose and hemicellulose but do not affect lignin and extractives (Fardim et al. 2006; Tomak 2013; Guo et al. 2015). Therefore, it is speculated that the red oak wooden components in the old wooden structures of Xichuan Guild Hall were easily affected by brown-rot fungi during their long-term use.
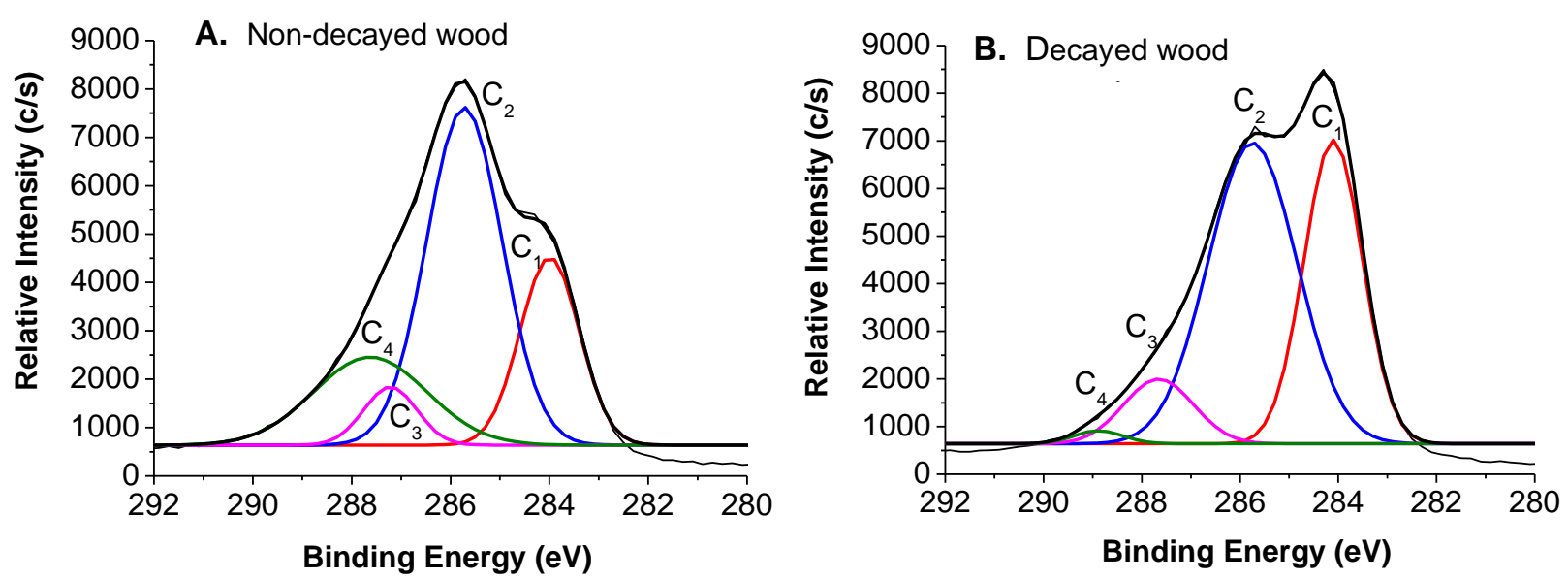

Fig. 2. The high resolution of $\mathrm{C} 1 \mathrm{~s}$ of the red oak wooden components

Table 3. Deconvoluted Peak Assignments with Corresponding Theoretical BE and Bond Type for High-Resolution XPS Scan Of C1s and O1s

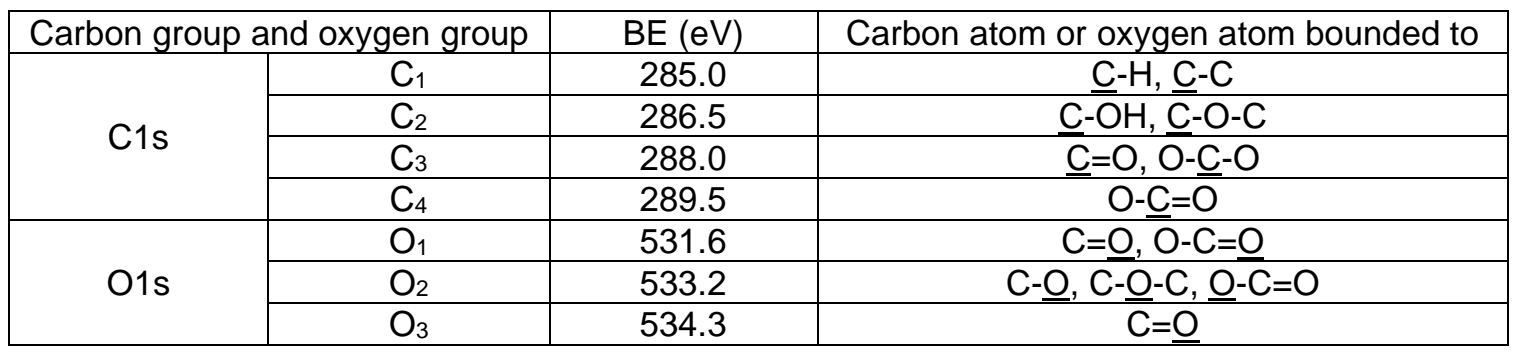


Table 4. Detailed Values of BE, Peak Area, and Cox/Cunox for Decomposed Oxygen Peaks (C1s) for All Samples

\begin{tabular}{|c|c|c|c|c|c|c|c|c|c|c|}
\hline \multirow{2}{*}{\multicolumn{2}{|c|}{ Samples }} & \multicolumn{4}{|c|}{$\mathrm{BE}$ of $\mathrm{C} 1 \mathrm{~s}(\mathrm{eV})$} & \multicolumn{4}{|c|}{ Peak Area of C1s (\%) } & \multirow{2}{*}{$\begin{array}{c}\text { Cox/ } \\
\text { Cunox }\end{array}$} \\
\hline & & $\mathrm{C}_{1}$ & $\mathrm{C}_{2}$ & $\mathrm{C}_{3}$ & $\mathrm{C}_{4}$ & $\mathrm{C}_{1}$ & $\mathrm{C}_{2}$ & $\mathrm{C}_{3}$ & $\mathrm{C}_{4}$ & \\
\hline \multirow{2}{*}{$\begin{array}{c}\text { NDRO } \\
\text { W }\end{array}$} & $\mathrm{M}$ & $\begin{array}{c}283.9 \\
9 \\
\end{array}$ & $\begin{array}{c}285.7 \\
2 \\
\end{array}$ & $\begin{array}{c}287.2 \\
2 \\
\end{array}$ & $\begin{array}{c}287.6 \\
2 \\
\end{array}$ & 22.40 & 51.32 & 6.23 & 20.05 & 3.46 \\
\hline & $\mathrm{S}$ & 1.22 & 1.89 & 0.41 & 1.22 & 1.34 & 2.14 & 1.02 & 0.87 & 1.05 \\
\hline \multirow{2}{*}{ DROW } & $\mathrm{M}$ & $\begin{array}{c}284.1 \\
0\end{array}$ & $\begin{array}{c}285.7 \\
5\end{array}$ & $\begin{array}{c}287.6 \\
6\end{array}$ & $\begin{array}{c}288.8 \\
8\end{array}$ & $\begin{array}{c}35.82 \\
\uparrow\end{array}$ & $\begin{array}{c}53.81 \\
\uparrow\end{array}$ & $9.09 \uparrow$ & $\begin{array}{c}1.28 \\
\downarrow\end{array}$ & $\stackrel{1.79}{\downarrow}$ \\
\hline & $\mathrm{S}$ & 0.58 & 1.37 & 1.26 & 0.98 & 0.48 & 2.14 & 1.35 & 1.22 & 0.89 \\
\hline \multicolumn{2}{|c|}{ Changes } & - & - & - & - & $\begin{array}{c}+59.91 \\
\%\end{array}$ & $\begin{array}{c}+4.85 \\
\%\end{array}$ & $\begin{array}{c}+45.91 \\
\%\end{array}$ & $\begin{array}{c}- \\
93.62 \\
\%\end{array}$ & $\begin{array}{c}- \\
48.27 \\
\%\end{array}$ \\
\hline \multirow{2}{*}{ NDHW } & $\mathrm{M}$ & $\begin{array}{c}283.9 \\
6 \\
\end{array}$ & $\begin{array}{c}285.5 \\
9 \\
\end{array}$ & $\begin{array}{c}287.0 \\
4 \\
\end{array}$ & $\begin{array}{c}289.7 \\
5 \\
\end{array}$ & 20.21 & 38.70 & 38.29 & 2.80 & 3.95 \\
\hline & $\mathrm{S}$ & 1.19 & 0.61 & 0.89 & 1.32 & 1.22 & 0.91 & 2.34 & 1.45 & 1.01 \\
\hline \multirow{2}{*}{ DHW } & $M$ & $\begin{array}{c}284.0 \\
7 \\
\end{array}$ & $\begin{array}{c}285.6 \\
2 \\
\end{array}$ & $\begin{array}{c}287.2 \\
9 \\
\end{array}$ & - & $\begin{array}{c}28.73 \\
\uparrow\end{array}$ & $\begin{array}{c}40.43 \\
\uparrow\end{array}$ & $\underbrace{30.83}$ & - & $\begin{array}{c}2.48 \\
\Downarrow\end{array}$ \\
\hline & $\mathrm{S}$ & 1.53 & 0.64 & 1.22 & - & 1.34 & 0.68 & 1.85 & - & 1.41 \\
\hline \multicolumn{2}{|c|}{ Changes } & - & - & - & - & $\begin{array}{c}+42.16 \\
\%\end{array}$ & $\begin{array}{c}+4.47 \\
\%\end{array}$ & $19 . \overline{-} 8 \%$ & - & $\begin{array}{c}37.22 \\
\%\end{array}$ \\
\hline
\end{tabular}

Ols spectra analysis of the wood surfaces

The deconvoluted peak assignments with corresponding theoretical BE and bond type for high-resolution XPS scan of O1s are presented in Table 5. Low BE values of 531.6 $\pm 0.4 \mathrm{eV}$ are attributed to oxygen atoms between two phenolic groups or an oxygen doublebonded to a carbon, i.e., $\mathrm{C}=\underline{\mathrm{O}}, \mathrm{O}-\mathrm{C}=\underline{\mathrm{O}}$ denoted as $\mathrm{O}_{1}$ (Hua et al. 1993). These components are associated to lignin, and an increase in $\mathrm{O}_{1}$ contribution indicates a relative increase in lignin and extractive contents but a decrease in carbohydrate contents on wood surfaces (Hua et al. 1993). All oxygen atoms bonded to carbon atoms with a single bond (C-O), i.e., $\mathrm{C}-\underline{\mathrm{O}}, \mathrm{C}-\underline{\mathrm{O}}-\mathrm{C}$, and $\underline{\mathrm{O}}-\mathrm{C}=\mathrm{O}$, are attributed to $\mathrm{O}_{2}$ component with a high $\mathrm{BE}$ value of 533.2 eV (Hua et al. 1993). These component are suggested to be associated to carbohydrates, and a decrease in $\mathrm{O}_{2}$ contribution indicates an increase in lignin and extractive contents but a decrease in carbohydrate contents on wood surfaces (Hua et al. 1993). The phenolic oxygen, i.e., $\mathrm{C}=\underline{\mathrm{O}}$ is attributed to the $\mathrm{O}_{3}$ component with the highest $\mathrm{BE}$ value of $534.3 \pm$ $0.4 \mathrm{eV}$ and is mainly associated with lignin in wood. Consequently, the $\mathrm{O}_{3}$ component in XPS spectra indicates the presence of lignin on the wood surfaces (Kocaefe et al. 2013).

The high-resolutions of O1s of the surfaces of red oak wooden components in decayed and non-decayed samples were deconvoluted into three subpeaks by using Origin 8.5 software as shown in Fig. 3. $\mathrm{O}_{1}, \mathrm{O}_{2}$, and $\mathrm{O}_{3}$ were contained in both samples. BE values, peak area, and $\left(\mathrm{O}_{1}+\mathrm{O}_{3}\right) / \mathrm{O}_{2}$ for decomposed carbon peaks $(\mathrm{O} 1 \mathrm{~s})$ from all samples are presented in Table 5. The $\mathrm{O}_{1}$ and $\mathrm{O}_{3}$ contributions increased noticeably from $2.55 \%$ to $5.99 \%$ and from $22.4 \%$ to $26.9 \%$, respectively, with increase percentages of approximately $20.3 \%$ and $134.9 \%$, respectively. These findings indicate that the carbohydrates were considerably decayed by fungi, leading to an increase in lignin content. $\mathrm{O}_{2}$ contributions decreased from $75.1 \%$ to $67.1 \%$ with decreased percentage of approximately $10.61 \%$ after decay, indicating a decrease in carbohydrate contents. 
The $\left(\mathrm{O}_{1}+\mathrm{O}_{3}\right) / \mathrm{O}_{2}$ increased noticeably from 0.33 to 0.49 with increase percentage of approximately $48.5 \%$. This finding indicates an increase in oxygen atoms that were doublebonded to carbon atoms, i.e., an increase in the carbonyl groups of lignin and the oxidation states of carbon atoms. This result was in good agreement with the study by $\mathrm{Xu}$ et al. (2013).

Basing on the $\mathrm{O} / \mathrm{C}$ analysis for $\mathrm{C}_{1}, \mathrm{C}_{2}, \mathrm{C}_{3}$, and $\mathrm{C}_{4}$ and $\mathrm{O}_{1}, \mathrm{O}_{2}$, and $\mathrm{O}_{3}$ contents of cellulose, hemicellulose, and lignin of the red oak wooden components, it was concluded that cellulose and hemicellulose were easily attacked by fungi compared with lignin.
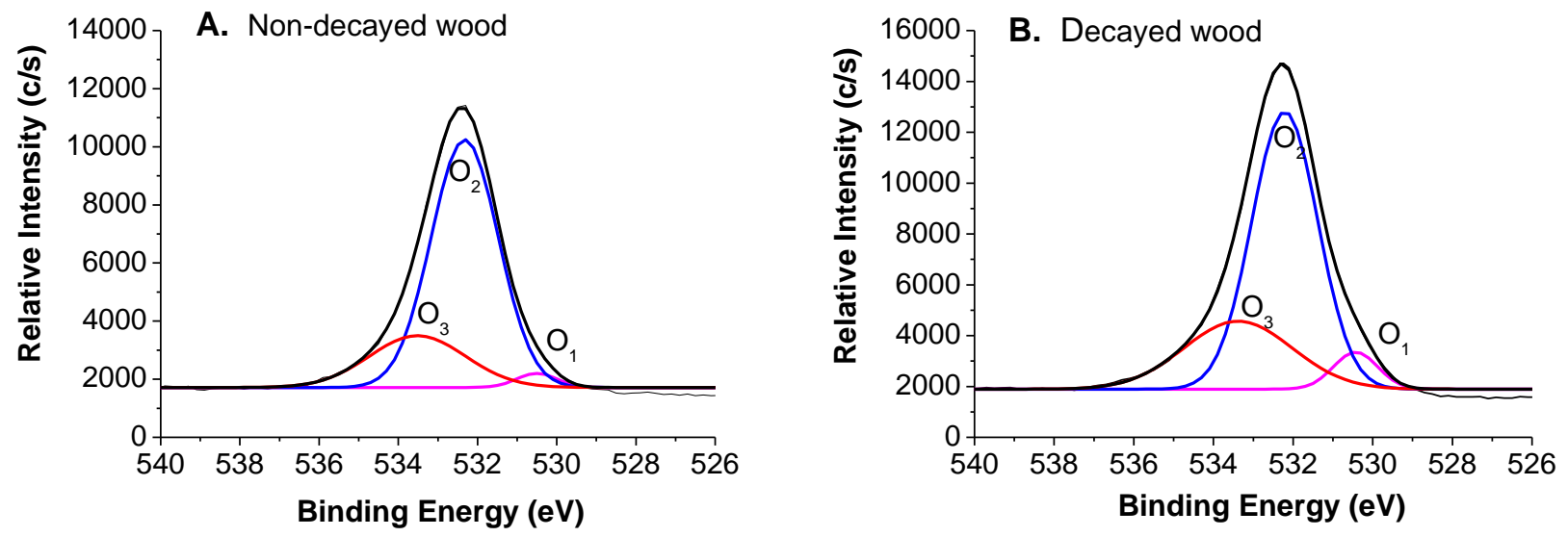

Fig. 3. The high resolution of $\mathrm{O} 1 \mathrm{~s}$ of the red oak wooden components

Table 5. Detailed Values of BE, Peak Area and $\left(\mathrm{O}_{1}+\mathrm{O}_{3}\right) / \mathrm{O}_{2}$ for Decomposed Carbon Peaks (O1s) for All Samples

\begin{tabular}{|c|c|c|c|c|c|c|c|c|}
\hline \multicolumn{2}{|c|}{ Samples } & \multicolumn{3}{c|}{$\mathrm{BE}$ of $\mathrm{O} 1 \mathrm{~s}(\mathrm{eV})$} & \multicolumn{3}{c|}{ Peak Area of O1s (\%) } & \multirow{2}{*}{$\left(\mathrm{O}_{1}+\mathrm{O}_{3}\right) / \mathrm{O}_{2}$} \\
\cline { 2 - 9 } & & $\mathrm{O}_{3}$ & $\mathrm{O}_{2}$ & $\mathrm{O}_{1}$ & $\mathrm{O}_{3}$ & $\mathrm{O}_{2}$ & $\mathrm{O}_{1}$ & \\
\hline \multirow{2}{*}{ NDROW } & $\mathrm{M}$ & 533.52 & 532.32 & 530.50 & 22.35 & 75.09 & 2.55 & 0.33 \\
\cline { 2 - 9 } & $\mathrm{S}$ & 1.92 & 0.85 & 1.54 & 1.25 & 1.96 & 2.03 & 1.33 \\
\hline \multirow{2}{*}{ DROW } & $\mathrm{M}$ & 533.38 & 532.21 & 530.43 & $26.88 \uparrow$ & $\begin{array}{c}67.12 \\
\downarrow\end{array}$ & $5.99 \uparrow$ & $0.49 \uparrow$ \\
\cline { 2 - 9 } & $\mathrm{S}$ & 1.89 & 1.21 & 1.36 & 2.31 & 1.59 & 1.63 & 1.68 \\
\hline \multirow{2}{*}{ Changes } & - & - & - & $+20.27 \%$ & - & $+134.90 \%$ & $+48.48 \%$ \\
\hline \multirow{2}{*}{ NDHW } & $\mathrm{M}$ & 533.47 & 532.25 & 530.42 & 45.69 & 51.56 & 2.75 & 0.94 \\
\cline { 2 - 9 } & $\mathrm{S}$ & 1.99 & 1.15 & 0.56 & 1.85 & 1.63 & 1.91 & 1.35 \\
\hline \multirow{2}{*}{ DHW } & $\mathrm{M}$ & 533.50 & 532.36 & 531.32 & $34.77 \downarrow$ & 49.32 & $15.91 \uparrow$ & $1.03 \uparrow$ \\
\cline { 2 - 8 } & $\mathrm{S}$ & 1.56 & 0.95 & 1.36 & 1.25 & 1.31 & 2.01 & 1.89 \\
\hline \multicolumn{2}{|c|}{ Changes } & - & - & - & $-23.90 \%$ & $-4.34 \%$ & $+478.55 \%$ & $+9.57 \%$ \\
\hline
\end{tabular}

\section{XPS Analysis of Hemor Wooden Components}

XPS survey spectra analysis of the wood surfaces

The survey XPS spectra of the surfaces of the hemor wooden components in decayed and non-decayed samples are presented in Fig. 4. The experimental atomic compositions, atomic percentages, and $\mathrm{O} / \mathrm{C}$ of wood surfaces were obtained by XPS analysis and are presented in Table 2 .

The relative content of $\mathrm{C}$ on the surface of the decayed hemor wood increased, whereas that of $\mathrm{O}$ decreased as shown in Fig. 4 and Table 2. Decaying slightly reduced the 
$\mathrm{O} / \mathrm{C}$ from 0.49 in the non-decayed wood to 0.47 in the decayed wood, and the decrease percentage was approximately $4.08 \%$. This result indicated a reduction in the predominant oxygen-containing functional groups on the decayed wood surface, that is, the relative content of lignin increased, whereas that of carbohydrates decreased. These findings were in good agreement with those of Li et al. (2018).
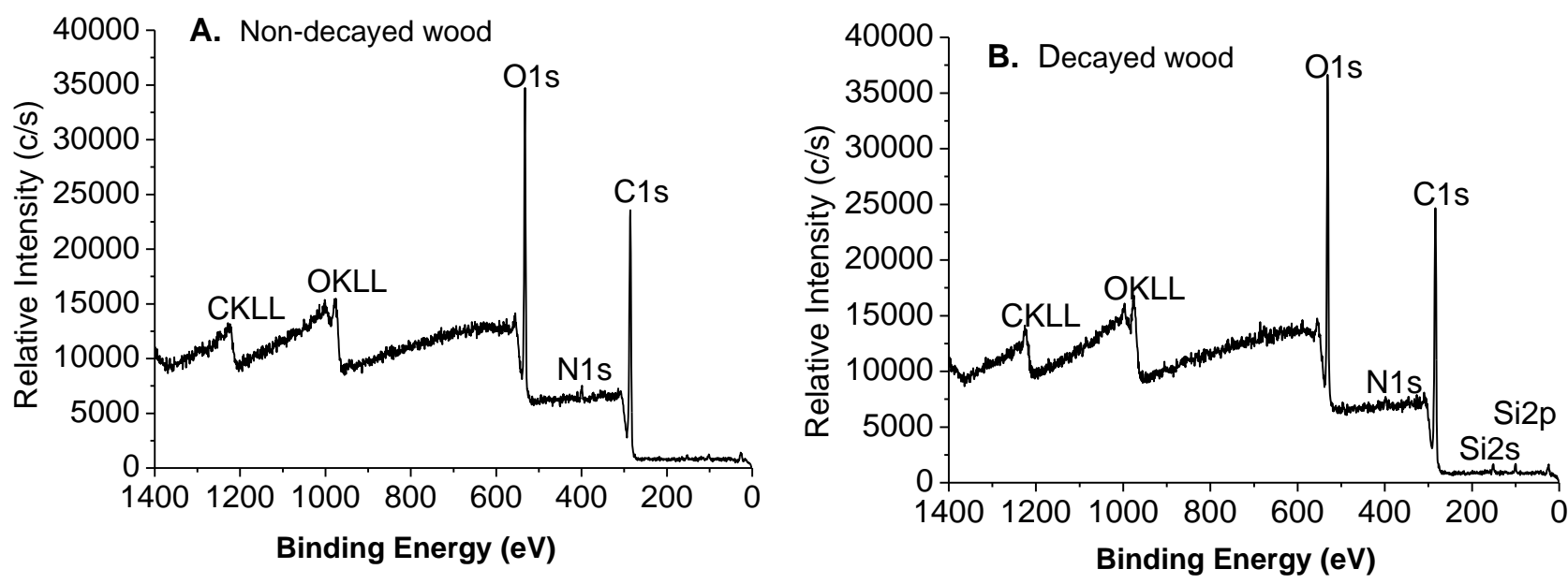

Fig. 4. XPS survey spectra of the hemor wooden components ("cps"s in all ordinates of the figures have been corrected by "c/s"s )

C1s spectra analysis of the wood surfaces

The high-resolution $\mathrm{C} 1 \mathrm{~s}$ of the surfaces of red oak wooden components in decayed and non-decayed samples were deconvoluted into four subpeaks by using Origin 8.5 software (Fig. 5). The detailed BE values and content of each carbon signal group are presented in Table 4 . The $\mathrm{C}_{1}$ contributions increased substantially from $20.2 \%$ to $28.7 \%$ with an increase percentage of approximately $42.2 \%$. This finding indicates that the carbohydrates were considerably decayed by fungi, and the $\mathrm{C}-\mathrm{C}$ bonds and contents of lignin and extractives were consequently increased. Meanwhile, the $\mathrm{C}_{2}$ contributions increased weakly from $38.7 \%$ to $40.4 \%$, indicating an increase in hydroxyl groups (-OH) mainly derived from cellulose and hemicellulose. On the contrary, $\mathrm{C}_{3}$ contributions decreased remarkably from $38.3 \%$ to $30.8 \%$ after decay with a decrease percentage of approximately $19.5 \%$. This finding indicates a decrease in the acetal structure (O-C-O) derived from cellulose and hemicellulose and in the carbonyl structure $(\mathrm{C}=\mathrm{O})$ of lignin. However, the $\mathrm{C}_{4}$ contributions decreased rapidly from $2.80 \%$ to $0 \%$, indicating that the hemicellulose was considerably decayed by fungi, leading to a sharp decrease in the acetyl groups and glucuronic acid present in the hemicellulose. These results revealed that the carbohydrates in hemor wooden components can be degraded by fungi as implied by the changes of the relative contents of $\mathrm{C}_{1}, \mathrm{C}_{2}, \mathrm{C}_{3}$, and $\mathrm{C}_{4}$. These findings were in good agreement with the results presented by $\mathrm{Xu}$ et al. (2013). By comparison, the decadent degree of carbohydrates by fungi was lower in the hemor wooden components than in the red oak wooden components.

The $\mathrm{C}_{\mathrm{ox}} / \mathrm{C}_{\text {unox }}$ decreased from 3.95 to 2.48 after decay, suggesting a decrease in the oxygen-containing functional groups during this process. These findings were in good agreement with the study by Xu et al. (2013). 

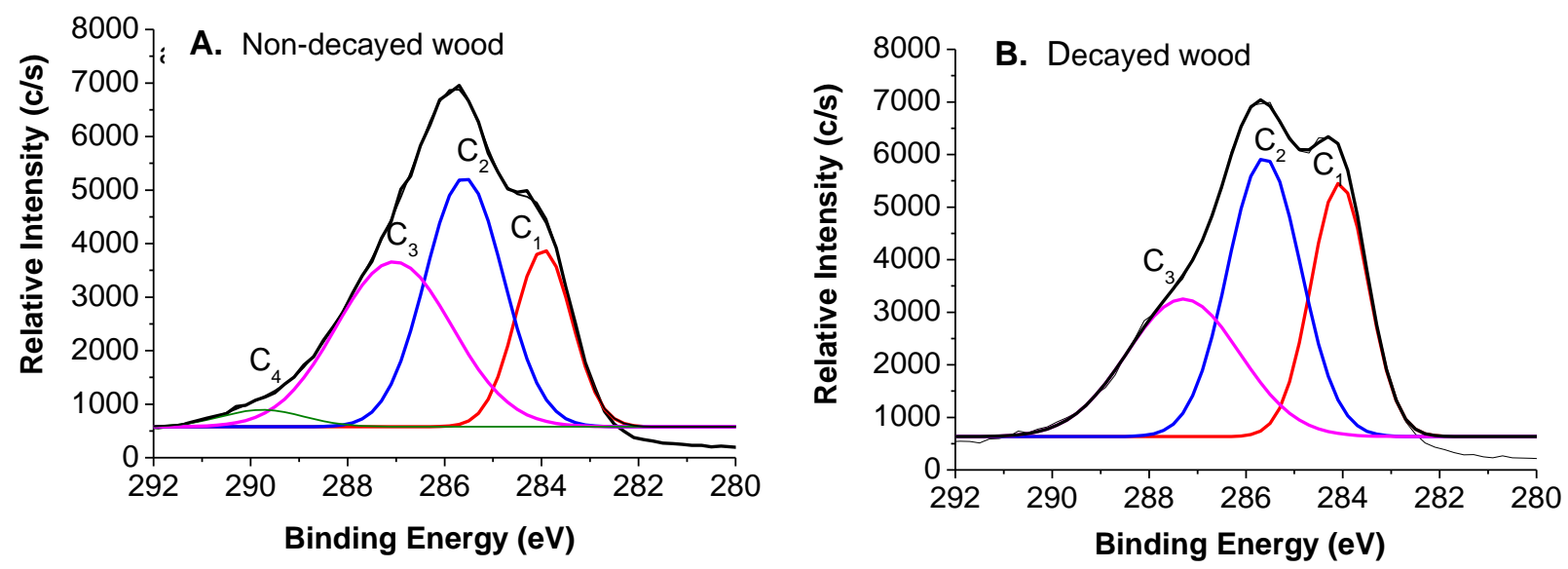

Fig. 5. The high resolution of $\mathrm{C} 1 \mathrm{~s}$ of the hemor wooden components

O1s spectra analysis of the wood surfaces

The high-resolutions of O1s of the surfaces of hemor wooden components in the decayed and non-decayed woods were deconvoluted into three subpeaks by using Origin 8.5 software. Figure 6 shows that $\mathrm{O}_{1}, \mathrm{O}_{2}$, and $\mathrm{O}_{3}$ were present in the decayed wood and the model specimen. The detailed BE values and content of each oxygen signal group are presented in Table 5. The $\mathrm{O}_{1}$ contributions increased noticeably from $2.75 \%$ to $15.9 \%$, a percentage increase of approximately $479 \%$. This finding indicates that lignin was attacked by fungi, and its content was consequently increased. The contributions of $\mathrm{O}_{2}$ decreased from $51.6 \%$ to $49.3 \%$ after decay with a decrease percentage of approximately $5.34 \%$, indicating a reduction in the cellulose content. However, the $\mathrm{O}_{3}$ contributions decreased from $45.7 \%$ to $34.8 \%$ with a decrease percentage of approximately $23.9 \%$, indicating a decadent of lignin and a decrease in its content.

The $\left(\mathrm{O}_{1}+\mathrm{O}_{3}\right) / \mathrm{O}_{2}$ increased from 0.94 to 1.03 , indicating an increase in the oxygen atoms double-bonded to carbon atoms, i.e., an increase was observed for the carbonyl groups in the lignin and the oxidation states of the carbon atoms. This result was in good agreement with the study by Xu et al. (2013).
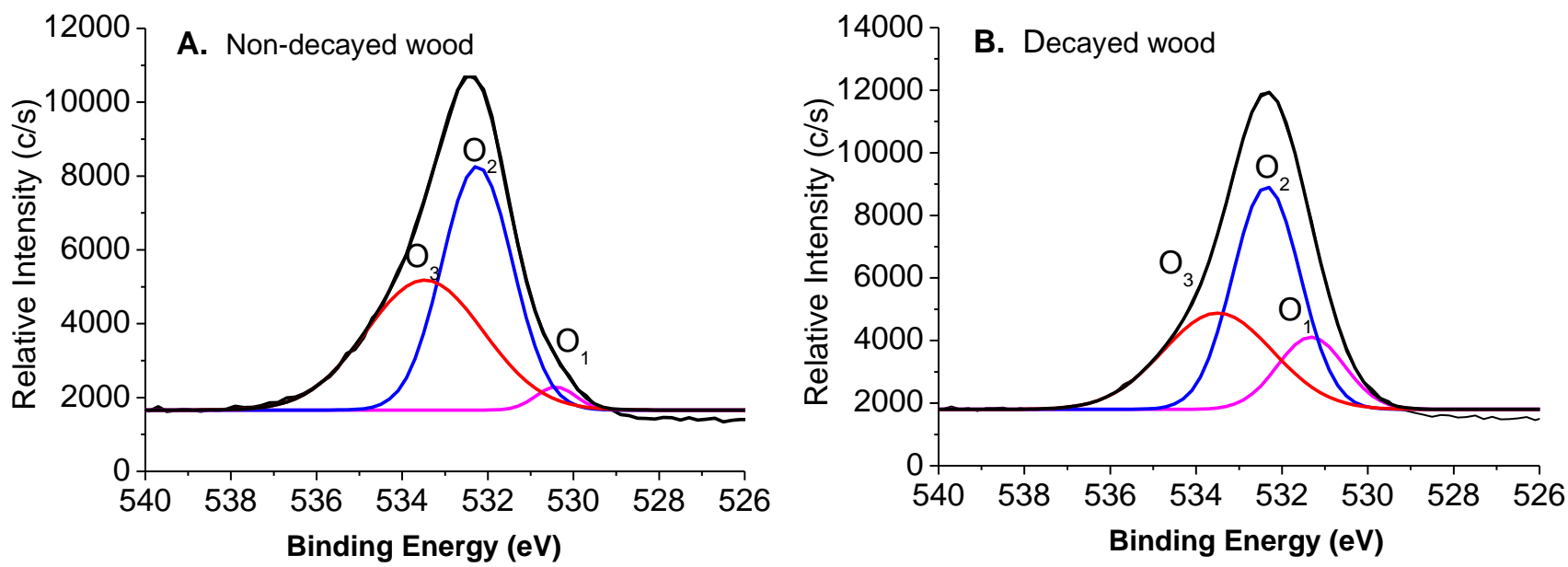

Fig. 6. The high resolution of O1s of the hemor wooden components 
The $\mathrm{O} / \mathrm{C}$ analysis revealed the $\mathrm{C}_{1}, \mathrm{C}_{2}, \mathrm{C}_{3}$, and $\mathrm{C}_{4}$ contents and, $\mathrm{O}_{2}, \mathrm{O}_{3}$ levels of cellulose, hemicellulose, and lignin of hemor wooden components. Based on these results, cellulose, hemicellulose, and lignin were all attacked by fungi.

\section{CONCLUSIONS}

1. Decaying reduced the $\mathrm{O} / \mathrm{C}$ ratio from 0.59 to 0.42 in the red oak wooden components, indicating that the oxygen-containing functional groups and carbohydrates decreased, whereas the relative lignin content increased. The contribution of $\mathrm{C}_{1}$ increased, those of $\mathrm{C}_{2}$ and $\mathrm{C}_{3}$ increased slightly, and that of $\mathrm{C}_{4}$ decreased. The contributions of $\mathrm{O}_{1}$ and $\mathrm{O}_{3}$ increased substantially, and that of $\mathrm{O}_{2}$ contributions decreased remarkably, indicating that the carbohydrates, especially cellulose, in red oak wooden components can be easily degraded by fungi compared with lignin.

2. Decaying reduced the $\mathrm{O} / \mathrm{C}$ from 0.49 to 0.47 in the hemor wooden components, indicating a slight decrease in the oxygen-containing functional groups and a reduction in the relative carbohydrate content. The contribution of $\mathrm{C}_{1}$ increased, that of $\mathrm{C}_{2}$ increased slightly, and those of $\mathrm{C}_{3}$ and $\mathrm{C}_{4}$ decreased. The contribution of $\mathrm{O}_{1}$ increased noticeably, those of $\mathrm{O}_{2}$ decreased substantially, but that of $\mathrm{O}_{3}$ decreased remarkably, indicating that carbohydrate and lignin were all degraded by fungi.

3. In comparison, the decay was lower in the hemor wooden components than in the red oak wooden components.

\section{ACKNOWLEDGMENTS}

The authors gratefully acknowledge financial supports from Natural National Science Foundation of China (31700481), Cross-science Research Project of Nanyang Institute of Technology (presented by Yan Yang), Scientific Research Start-up Projects of Nanyang Institute of Technology (presented by Yan Yang and Wei Wang). He Sun and Yan Yang contributed equally to this work, and they are the first authors.

\section{REFERENCES CITED}

Arias, M.-E., Rodríguez, J., Pérez, M.-I., Hernández, M., Polvillo, O., González-Pérez, J.A., and González-Vila, F.-J. (2010). "Analysis of chemical changes in Picea abies wood decayed by different Streptomyces strains showing evidence for biopulping procedures," Wood Science and Technology 44(2), 179-188. DOI: 10.1007/s00226009-0282-1

Banuls-Ciscar, J., Pratelli, D., Abel, M.-L., and Watts, J.-F. (2016). "Surface characterisation of pine wood by XPS," Surface and Interface Analysis 48(7), 589592. DOI: $10.1002 /$ sia.5960

Bari, E., Daryaei, M.-G., Karim, M., Bahmani, M., Schmid, O., Woodward, S., TajickGhanbary, M.-A., and Sistani, A. (2019). "Decay of Carpinus betulus wood by Trametes versicolor - An anatomical and chemical study," International Biodeterioration and Biodegradation 137, 68-77. DOI: 10.1016/j.ibiod.2018.11.011 
Brischke, C., Stricker, S., Meyer-Veltrup, L., and Emmerich, L. (2019). "Changes in sorption and electrical properties of wood caused by fungal decay," Holzforschung 73 (5), 445-455. DOI: 10.1515/hf-2018-0171

Chang, L., Rong, B., Xu, G., Meng, Q., and Wang, L. (2019). "Mechanical properties., components and decay resistance of Populus davidiana bioincised by Coriolus versicolor," Journal of Forestry Research. DOI: 10.1007/s11676-019-00972-3

Choi, J.-W., Choi, D.-H., Ahn, S.-H., Lee, S.-S., Kim, M.-K., Meier, D., Faix, O., and Scott, G.-M. (2006). "Characterization of trembling aspen wood (Populus tremuloides L.) degraded with the white rot fungus Ceriporiopsis subvermispora and MWLs isolated thereof," Holz als Roh- und Werkstoff 64 (5), 415-422. DOI: 10.1007/s00107-006-0133-9

Croitoru, C., Spirchez, C., Lunguleasa, A., Cristea, D., Roata, I.-C., Pop, M.-A., Bedo, T., Stanciu, E.-M., and Pascu, A. (2018). "Surface properties of thermally treated composite wood panels," Applied Surface Science 438, 114-126. DOI:

10.1016/j.apsusc.2017.08.193

Dey, S., Maiti, T.-K., Sreemany, M., Ghosh, T.-B., and Bhattacharyya, B.-C. (1992). "Characterization of white-rotted and brown-rotted rice straw by X-ray photoelectron spectroscopy," Holzforschung 46(5), 385-390.

Fardim, P., Hultén, A.-H., Boisvert, J.-P., Johansson, L.-S., Ernstsson, M., Campbell, J.M., Lejeune, A., Holmbom, B., Laine, J., and Gray, D. (2006). "Critical comparison of methods for surface coverage by extractives and lignin in pulps by X-ray photoelectron spectroscopy (XPS)," Holzforschung 60(2), 149-155.

Fernández-Fernández, M., Sanromán, M.-A., and Moldes, D. (2014). "Potential of laccase for modification of Eucalyptus globulus wood: A XPS study," Wood Science and Technology 48(1), 151-160. DOI: 10.1007/s00226-013-0593-0

Ferraz, A., and Durán, N. (1995). "Lignin degradation during softwood decaying by the ascomycete Chrysonilia sitophila," Biodegradation 6(4), 265-274. DOI: 10.1007/BF00695257

Gao, S., Wang, L.-H., and Yue, X.-Q. (2019). "Effect of the degree of decay on the electrical resistance of wood degraded by brown-rot fungi," Canadian Journal of Forest Research 49, 145-153. DOI: 10.1139/cjfr-2018-0282

Guo, M.-L., Lan, H.-F., and Qiu, J. (2015). Wood Deterioration and Preservation, China Metrology Publishing House, Beijing, China.

Huang, X.-A., Kocaefe, D., Kocaefe, Y., Boluk, Y., and Pichette, A. (2012). "Study of the degradation behavior of heat-treated jack pine (Pinus banksiana) under artificial sunlight irradiation," Polymer Degradation and Stability 97 (7), 1197-1214. DOI: 10.1016/j.polymdegradstab.2012.03.022

Inari, G.-N., Pétrissans, M., Dumarcay, S., Lambert, J., Ehrhardt, J.-J., Šernek, M., and Gérardin, P. (2011). "Limitation of XPS for analysis of wood species containing high amounts of lipophilic extractives," Wood Science and Technology 45(2), 369-382. DOI: $10.1007 / \mathrm{s} 00226-010-0324-8$

Inari, G.-N., Pétrissans, M., Lambert, J., Ehrhardt, J.-J., and Gérardin, P. (2006). "XPS characterization of wood chemical composition after heat-treatment," Surf. Interface Anal. 38(10), 1336-1342. DOI: 10.1002/sia.2455

Kocaefe, D., Huang, X., Kocaefe, Y., and Boluk, Y. (2013). "Quantitative characterization of chemical degradation of heat-treated wood surfaces during artificial weathering using XPS,” Surf. Interface Anal. 45(2), 639-649. DOI: 10.1002/sia.5104

Koyani, R.-D., and Rajput, K.-S. (2014). "Light microscopic analysis of Tectona grandis 
L.f. wood inoculated with Irpex lacteus and Phanerochaete chrysosporium," European Journal of Wood and Wood Products 72(2),157-164. DOI: 10.1007/s00107-013-0763-7

Li, Q., Qi, W.-Y., Ren, K., and Lin, J.-G. (2018). "Biodegradation of Pinus massoniana by brown-rot fungi based on X-ray photoelectron spectroscopy," Journal of Southwest Forestry University 38(3),188-193. DOI: 10.11929/j.issn.2095-1914.2018.03.027

Li, S., Gao, Y., Brunetti, M., Macchioni, N., Nocetti, M., and Palanti, S. (2019). "Mechanical and physical properties of Cunninghamia lanceolata wood decayed by brown rot," Forest 12, 317-322. DOI: 10.3832/ifor2922-012

Matuana, L.-M., and Kamdem, D.-P. (2002). "Accelerated ultraviolet weathering of PVC/wood-flour composites," Polymer Engineering \& Science 42 (8), 1657-1666. DOI: $10.1002 /$ pen.11060

Popescu, C.-M., Tibirna, C.-M., and Vasile, C. (2009). "XPS characterization of naturally aged wood," Applied Surface Science 256(5), 1355-1360. DOI: 10.1016/j.apsusc.2009.08.087

Stark, N.-M., and Matuana, L.-M. (2004). "Surface chemistry changes of weathered HDPE/wood-flour composites studied by XPS and FTIR spectroscopy," Polymer Degradation and Stability 86(1), 1-9. DOI: 10.1016/j.polymdegradstab.2003.11.002.

Stark, N.-M., and Matuana, L.-M. (2007). "Characterization of weathered wood-plastic composite surfaces using FTIR spectroscopy., contact angle., and XPS. Polymer Degradation and Stability 92(10), 1883-1890," DOI: 10.1016/j.polymdegradstab.2007.06.017

Tomak, E.-D., Topaloglu, E., Gumuskaya, E., Yildiz, U.-C., and Ay, N. (2013). “An FTIR study of the changes in chemical composition of bamboo degraded by brown-rot fungi," International Biodeterioration and Biodegradation 85, 131-138. DOI: 10.1016/j.ibiod.2013.05.029

Wang, X.-Q., Ren, H.-Q., Zhao, R.-J., Cheng, Q., and Chen, Y.-P. (2009). "FTIR and XPS spectroscopic studies of photodegradation of moso bamboo (Phyllostachys pubescens Mazel)," Spectroscopy and Spectral Analysis 29 (7), 1864-1867. DOI:

10.3964/j.issn.1000-0593(2009)07-1864-04

Xu, G.-Q., Wang, L.-H., Liu, J.-L., and Wu, J.-Z. (2013). "FTIR and XPS analysis of the changes in bamboo chemical structure decayed by white-rot and brown-rot fungi," Applied Surface Science 280, 799-805. DOI: 10.1016/j.apsusc.2013.05.065.

Yang, Y., Dong, C.-L., Luo, B., Chen, T.-A., and Lu, J.-X. (2018). "Characterization of wood surface elemental compositions after thermo-vacuum treatment and superheated-steam heat treatment," BioResources 13(1), 1895-1908. DOI: 10.15376/biores.13.1.1895-1908

Yang, Y., Sun, H., Li, B., Han, L., Wang, A.-F., Wang, W., He, Y.-M., and Zhao, R. (2020). "Study on the identification and the extent of decay of the wooden components in the Xichuan Guild Hall ancient architectures," International Journal of Architectural Heritage. DOI:10.1080/15583058.2020.1786190.

Article submitted: April 27, 2020; Peer review completed: June 21, 2020; Revised version received and accepted: June 24, 2020; Published: July 2, 2020.

DOI: $10.15376 /$ biores. 15.3.6332-6343 